\title{
Consensus-based care recommendations for adults with myotonic dystrophy type 1
}

Tetsuo Ashizawa, MD, Cynthia Gagnon, PhD, William J. Groh, MD, MPH, Laurie Gutmann, MD, Nicholas E. Johnson, MD, Giovanni Meola, MD, Richard Moxley III, MD, Shree Pandya, DPT, Mark T. Rogers, MD, Ericka Simpson, MD, Nathalie Angeard, PhD, Guillaume Bassez, MD, PhD, Kiera N. Berggren, MA, MS, Deepak Bhakta, MD, Marco Bozzali, MD, Ann Broderick, MD, MS, Janice L.B. Byrne, MD, Craig Campbell, MD, Edith Cup, PhD, John W. Day, MD, PhD, Elisa De Mattia, PT, Denis Duboc, MD, Tina Duong, MPT, PhDc, Katy Eichinger, PhD, Anne-Berit Ekstrom, MD, PhD, Baziel van Engelen, MD, PhD, Belen Esparis, MD, Bruno Eymard, MD, Marla Ferschl, MD, Shahinaz M. Gadalla, MD, PhD, Benjamin Gallais, PhD, Todd Goodglick, MD, Chad Heatwole, MD, James Hilbert, MS, Venessa Holland, MD, MPH, Marie Kierkegaard, PhD, Wilma J. Koopman, NP, PhD, Kari Lane, RD, Daphne Maas, PT, MSc, Ami Mankodi, MD, Katherine D. Mathews, MD, Darren G. Monckton, PhD, David Moser, PhD, Saman Nazarian, MD, PhD, Linda Nguyen, MD, Peg Nopoulos, MD, Richard Petty, MD, Janel Phetteplace, MS, Jack Puymirat, MD, PhD, Subha Raman, MD, Louis Richer, PhD, Elisabetta Roma, MD, Jacinda Sampson, MD, PhD, Valeria Sansone, MD, PhD, Benedikt Schoser, MD, Laurie Sterling, MS, Jeffrey Statland, MD, S.H. Subramony, MD, Cuixia Tian, MD, Careniña Trujillo, RN, MSN, Gordon Tomaselli, MD, Chris Turner, MD, PhD, Shannon Venance, MD, PhD, Aparajitha Verma, MD, Molly White, MA, and Stefan Winblad, PhD on behalf of the Myotonic Dystrophy Foundation

Neurology: Clinical Practice December 2018 vol. 8 no. 6 507-520 doi:10.1212/CPJ.0000000000000531

\section{Correspondence}

Dr. White

molly.white@myotonic.org

\section{Abstract}

\section{Purpose of review}

Myotonic dystrophy type 1 (DM1) is a severe, progressive genetic disease that affects between 1 in 3,000 and 8,000 individuals globally. No evidence-based guideline exists to inform the care of these patients, and most do not have access to multidisciplinary care centers staffed by experienced professionals, creating a clinical care deficit.

\section{Recent findings}

The Myotonic Dystrophy Foundation (MDF) recruited 66 in-

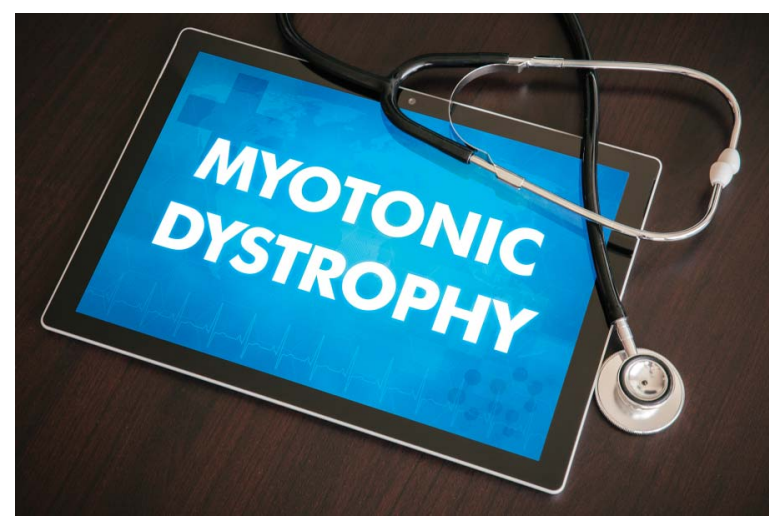
ternational clinicians experienced in DM1 patient care to develop consensus-based care recommendations. MDF created a 2-step methodology for the project using elements of the Single Text Procedure and the Nominal Group Technique. The process generated a 4-page Quick Reference Guide and a comprehensive, 55-page document that provides clinical care recommendations for 19 discrete body systems and/or care considerations.

\section{Summary}

The resulting recommendations are intended to help standardize and elevate care for this patient population and reduce variability in clinical trial and study environments.

Described as "one of the more variable diseases found in medicine," myotonic dystrophy type 1 (DM1) is an autosomal dominant, triplet-repeat expansion disorder that affects somewhere between 1:3,000 and 1:8,000 individuals worldwide. ${ }^{1}$ There is a modest association between

Funding information and disclosures are provided at the end of the article. Full disclosure form information provided by the authors is available with the full text of this article at Neurology.org/cp.

The Article Processing Charge was funded by the Myotonic Dystrophy Foundation.

This is an open access article distributed under the terms of the Creative Commons Attribution-NonCommercial-NoDerivatives License 4.0 (CC BY-NC-ND), which permits downloading and sharing the work provided it is properly cited. The work cannot be changed in any way or used commercially without permission from the journal. 
Comprehensive evidence-based guidelines do not currently exist to guide the treatment of DM1 patients.

increased repeat expansion and disease severity, as evidenced by the average age of onset and overall morbidity of the condition. An expansion of over 35 repeats typically indicates an unstable and expanding mutation. An expansion of 50 repeats or higher is consistent with a diagnosis of DM1. DM1 is a multisystem and heterogeneous disease characterized by distal weakness, atrophy, and myotonia, as well as symptoms in the heart, brain, gastrointestinal tract, endocrine, and respiratory systems. Symptoms may occur at any age. The severity of the condition varies widely among affected individuals, even among members of the same family.

Comprehensive evidence-based guidelines do not currently exist to guide the treatment of DM1 patients. As a result, the international patient community reports varied levels of care and care quality, and difficulty accessing care adequate to manage their symptoms, unless they have access to multidisciplinary neuromuscular clinics.

Consensus-based care recommendations can help standardize and improve the quality of care received by DM1 patients and assist clinicians who may not be familiar with the significant variability, range of symptoms, and severity of the disease. Care recommendations can also improve the landscape for clinical trial success by eliminating some of the inconsistencies in patient care to allow more accurate understanding of the benefit of potential therapies.

\section{Methods}

The Myotonic Dystrophy Foundation (MDF) recruited clinicians from the United States, United Kingdom, Canada, and Europe who have experience in the treatment of individuals living with DM1 to develop consensus-based care recommendations.

The project included a Steering Committee of 10 and a total Working Group of 66 clinical professionals, with additional support from the US Centers for Disease Control and Prevention and the services of a facilitation firm, Interaction Associates (San Francisco), that provided the meeting facilitation necessary to execute the Nominal Group Technique portion of the methodology. MDF provided project design, development, and management support.

To streamline the project timeline and lower project cost, MDF developed a 2-phased, consensus-building methodology using components of the Single Text Procedure ${ }^{2}$ and the Nominal Group Technique. ${ }^{3-5}$ These facilitation approaches were selected because they could be effective within the context of the limited clinical care data available for DM1, the clinical content already available, and the complexities of working across a large, multinational group of experts.

The Working Group was divided into 8 Study Area subcommittees, each led by a Steering Committee chair who identified members for his or her Study Area. The Study Areas were each assigned several body systems affected by myotonic dystrophy.

Working Group subcommittee members began the consensus-building project by creating the background reading lists for their Study Areas. These reading lists were refined as the project moved forward, and the Study Area lists serve as the bibliography for the final Consensus-based Recommendations.

The Single Text Procedure, using a single document as a starting point to incorporate the input and contributions of stakeholders, was used to begin the consensus-building effort. In this process, stakeholders add, subtract, and refine a draft text that becomes the foundation for a final ratified document.

Working with MDF, Margaret Wahl, RN, organized the draft document, drawing substantially from care content in the MDF Toolkit developed by the MDF's Scientific and Medical Advisory Committee, as well as several other key references. $^{6-9} \mathrm{MDF}$ circulated the draft document to Working Group members, along with other materials designed to help coordinate the editing and revision process. Working Group members read the draft content for their Study Areas and provided Study Area-specific recommendations. MDF aggregated all the revisions and suggestions into a single updated document. Recommendations in conflict were circulated to the group for discussion and resolved through serial conference calls.

The Steering Committee reviewed the aggregated document, offered revisions, and then returned it to the full Working Group. This process was repeated until the Steering Committee and Working Group achieved consensus.

Sixty-six Steering Committee and Working Group members then met for a face-to-face summit that involved the second phase of the project, the Nominal Group Technique.

The Nominal Group Technique is a face-to-face, structured group meeting led by an experienced facilitator. Participants engage in a serial discussion of each revised, updated, or newly-generated recommendation led by the facilitator. MDF engaged 7 professional facilitators from Interaction Associates to drive consensus building in Study Area subcommittee meetings at the summit. 
MDF then created an updated document aggregating the changes from the facilitated discussions, and the full Working Group went through the same facilitated process again with the new document, which concluded the Nominal Group Technique portion of the process.

MDF then created a postsummit, updated document based on full-group feedback at the meeting. This version was used to conduct a final series of rounds of edit solicitation and updated document review through email and conference call. These efforts led to the final consensus-based care recommendations and Quick Reference Guide for Adults with DM1, which were completed in mid-2017. The Quick Reference Guide is provided as an appendix, and the full document is available online (appendix e-1, links.lww.com/CPJ/ A53). Both feature flowcharts and other infographics for ease of use.

\section{Results}

See full recommendations at Neurology.org/cp.

\section{Life threatening symptoms-Clinical care recommendations}

- Surgery, anesthesia, and pain

- See MDF's Practical Suggestions for the Anesthetic Management of a Myotonic Dystrophy Patient (myotonic.org/clinical-resources) for anesthesia risks and recommendations before any surgeries or procedures requiring anesthesia.

- DM1 patients have adverse reactions to medications used for anesthesia and analgesia, including opioids; interactions of the cardiac, respiratory, muscle, and CNS manifestations in each DM1 patient can lead to a variety of untoward responses, including mortality, before, during, and after surgery.

- Serious adverse events to anesthesia and opioids can occur throughout the course of DM1 and have been reported in patients whose DM1 symptoms were mild.

- Intellectual impairment, cognitive dysfunction, and/ or hypersomnolence may adversely affect the patient's ability to re-emerge from anesthesia. Include premorbid cognitive or intellectual dysfunction as part of preoperative assessment preoperatively (if nonemergency intervention) because these manifestations along with preoperative sleep deprivation can complicate the patient's immediate postoperative care and long-term recovery.

- Most serious complications occur in the postanesthesia period.

- See full recommendations at myotonic.org/clinicalresources.

- Respiratory symptoms

- Pulmonary complications are the leading cause of death in DM1 patients. Clinicians must monitor issues such as recurrent pneumonia at baseline and serially
( \pm 6 months), with pulmonary function tests, at least forced vital capacity (FVC).

ORefer DM1 patients with respiratory symptoms including ineffective cough (normal peak expiratory cough flow rate is $>270 \mathrm{~L} / \mathrm{min}$ ), respiratory insufficiency, recurrent pulmonary infections, prominent snoring, maximal inspiratory pressure is $<60 \mathrm{~cm} \mathrm{H}_{2} \mathrm{O}$ or FVC values of $50 \%$ less than predicted normal values to a pulmonologist knowledgeable in neuromuscular disorders.

$\circ$ Vaccinate for pneumonia and flu; treat respiratory infections quickly and use cough assistance and mechanical ventilation as needed along with obtaining consultations from respiratory therapy and pulmonary medicine groups.

- Some patients will eventually require either nighttime ventilator support or full-time ventilation. Most patients with chronic respiratory insufficiency respond to noninvasive ventilatory support (NIV). Patients experiencing acute respiratory failure require endotracheal intubation with positive pressure ventilation.

○ For chronic respiratory insufficiency, use supplemental oxygen with caution and in conjunction with NIV (see Surgery, anesthesia, and pain).

If surgery is planned, reassess clearance capacity if needed, possible adaptation to NIV or cough assistance.

o See full recommendations at myotonic.org/clinicalresources.

- Cardiovascular symptoms

- Cardiac complications are the second leading cause of death in DM1.

$\circ$ The most common cardiac issues are arrhythmias (sinus bradycardia, heart block, atrial fibrillation and flutter, and ventricular tachycardia).

○ Palpitations, chest pain, dyspnea, orthopnea, lightheadedness, and syncope warrant cardiac investigation.

- Significant cardiac involvement that subsequently leads to adverse cardiac events is often asymptomatic.

- Impulse-conduction abnormalities on a standard 12-lead ECG including sinus rate $<50 \mathrm{BPM}, \mathrm{PR}$ interval $>200 \mathrm{~ms}$, QRS duration $>100 \mathrm{~ms}$, left anterior or posterior fascicular block, abnormal Qwaves, atrial tachycardia, fibrillation, or flutter, and ventricular arrhythmias are indicative of cardiac involvement.

- Refer patients with cardiac symptoms, abnormal annual or biennial ECG indicative of cardiac involvement, and patients aged above 40 years without previous cardiac evaluation to a center experienced in DM1 care.

- Cardiology referral for all DM1 patients is reasonable if part of a multidisciplinary program or if the practitioners providing primary care are uncomfortable assessing cardiac history, examination, or ECG.

- See full recommendations at myotonic.org/clinicalresources. 
- Pregnancy and obstetric management

○ Women with DM1:

- Have increased risk of miscarriage, preterm delivery, and respiratory insufficiency during pregnancy (especially in the 3rd trimester) and failed labor during delivery; extreme care should be taken with analgesics and sedating anesthetic drugs (see MDF's Practical Suggestions for the Anesthetic Management of a Myotonic Dystrophy Patient [myotonic.org/clinicalresources]).

- Should consult with a high-risk obstetrics and gynecology (OBGYN) care provider before delivery and obtain ongoing antenatal care.

- Fatigue rapidly during labor and are at risk of postpartum hemorrhage, particularly after prolonged first or second stage or if there has been polyhydramnios.

- Should be induced only at direction of obstetrician and after all necessary consultants assisting with the delivery are notified.

○ Sexually active patients with DM1:

- Should be referred to genetic counseling and family planning services if of child-bearing age.

- Should receive parental counselling for prenatal genetic diagnosis or discussion of preimplantation genetic diagnosis.

O Include a pediatric or neonatal specialist present at delivery; intensive neonatal care is recommended for neonates that may have DM1; anticipate need for feeding tube and ventilator support.

- Access to a pediatric or neonatal specialist is recommended even if the fetus is known to be unaffected.

o See full recommendations at myotonic.org/clinicalresources.

\section{Severe symptoms and conditions-Clinical care recommendations}

- Skeletal muscle weakness and rehabilitation

$\circ$ Evaluate annually for:

- Swallowing and speech difficulties

- Mobility, balance, and falls

- Activities of daily life-including self-care

- Activities in home, school, work, and community.

Refer to specialists, including physical therapists (PTs), occupational therapists (OTs), speech pathologists, dieticians, social workers, and others.

$\circ$ Encourage moderate intensity (aerobic and resistance training) exercise.

- See Role of Physical Therapy in the Assessment of Individuals with Myotonic Dystrophy at myotonic.org/ clinical-resources.

- See full recommendations at myotonic.org/clinicalresources.

- Skeletal muscle myotonia

- Myotonia can cause muscle stiffness, prolonged hand grip, pain, and speech and swallowing difficulties.
- Mexiletine or other antimyotonia medications may be considered for myotonia treatment. Mexiletine is contraindicated for DM1 patients with cardiac involvement. See full recommendations regarding mexiletine at myotonic.org/clinical-resources for more information on cardiac implications.

- Ocular symptoms

- Relevant eye manifestations of DM1 include cataracts (occurring in most patients), strabismus, and other ocular motility problems, myopia, and astigmatism in congenital and juvenile-onset patients.

$\circ$ Recommend annual eye examination, including slitlamp eye examination.

$\bigcirc$ Advise patient on safety measures regarding adjusting to changes in light (from dim to bright) while driving, especially at night, related to the effects of cataracts, and on protecting the cornea, especially as weakness of the face (due to m. orbicularis oculi weakness) and eye closure muscles progress.

- Surgically remove cataracts when they interfere with activities of daily living; see Surgery, anesthesia, and pain control section regarding anesthesia risk.

- Consider ophthalmic lubricants for dry eye, typically caused by $\mathrm{m}$. orbicular oculi weakness affecting eyelids and cornea.

- Consider eyelid crutches before surgery for ptosis (due to m. levator palpebrae weakness); see Surgery, anesthesia, and pain control.

- See full recommendations at myotonic.org/clinicalresources.

- Gastrointestinal symptoms

$\circ$ Ask about problems with chewing, swallowing, drooling, reflux, bloating, abdominal pain, bowel movement frequency and characteristics, diarrhea, and incontinence.

o Physical examination should include abdominal palpation, including around gall bladder, and rectal examination for anal sphincter spasm and dyssynergic defecation for symptomatic patients.

$\circ \mathrm{DM} 1$ patients are at risk for pseudo-obstruction and experience other problems that may cause actual obstruction of small or large intestine, including endometriosis, acute gallbladder inflammation, ruptured ovarian cysts, sigmoid volvulus. Monitor potential obstructions to determine whether they are pseudo or actual and treat accordingly.

- Nonmedical interventions:

- High-fiber diet for diarrhea or constipation; increase water intake

- Nutritional supplement for weight loss, weight gain, or dysphagia

- Dysphagia therapy referral for oral pharyngeal dysphagia.

$\circ$ Medical interventions:

- Loperamide for diarrhea control

- Laxatives for constipation 
- First-line therapy: MiraLAX, Senna, Ducusate, or Linaclotide

- Second-line therapy: Bisacodyl, Lubiprostone, Linaclotide

- Avoid oils-if the above fails, refer out for anal manometry

- Metoclopramide for gastroparesis, pseudoobstruction, reflux

- Antibiotics for bacterial overgrowth-induced diarrhea (based on breath testing)

- Enteral feeding only for recurring pneumonia or severe dysphagia causing weight loss or causing inability to swallow safely without recurrent aspiration

- Mexiletine can be considered to treat diarrhea or constipation. Mexiletine is contraindicated for DM1 patients with cardiac involvement. See full recommendations regarding mexiletine at myotonic.org/clinical-resources for more information on cardiac implications.

- See full recommendations at myotonic.org/clinicalresources.

- Neuropsychiatric symptoms

O Advise patients that DM1 is also a "brain disorder" that can involve cognitive deficits and changes in cognition over time.

- Include psychiatric and behavioral examination at baseline, and during regularly scheduled follow-up appointments or when symptoms appear; consider baseline MRI to assess DM1-related abnormalities (e.g., fluid-attenuated inversion recovery hyperintensities, particularly in the temporal poles, and dilated perivascular spaces, often colocalizing) and track over time.

- Refer patients with psychiatric or behavioral disorders, those with late-onset phenotype, and patients with cognitive complaints to mental health care professional for testing and follow-up; patients may have limited insight into these issues-consider input from partners and family members as appropriate.

- DM1 patients with a late-onset phenotype can exhibit fast decline in certain cognitive functions.

- See full recommendations at myotonic.org/clinicalresources.

- Psychosocial symptoms

- Assess patient's social circumstances in household; consider and be aware of possible child neglect, acute financial need, unsafe driving, unsafe or unsanitary home; refer to social services, support programs, and organizations.

- Excessive daytime sleepiness (EDS) symptoms

$\circ$ Assess for EDS with the Epworth Sleepiness Scale or a similar standardized questionnaire instrument; prescribe sleep study if sleep disturbance is suspected.

- Monitor periodic limb movements (muscle activity during sleep), as well as EEG, and respiratory measures during sleep study to assess possible obstructive sleep apnea and CNS mediated sleep apnea.

$\circ$ Refer to a pulmonologist and/or sleep specialist if EDS scores are positive on scales.

$\circ$ Question patients re: alcohol or caffeine consumption, medications, and sleep habits for contribution to EDS.

$\circ$ Evaluate the effect of possible respiratory muscle weakness (FVC value sitting and supine) on the presence of EDS.

O If nocturnal or daytime hypoventilation is suspected, consider noninvasive positive pressure ventilation, and refer to a pulmonologist with experience in neuromuscular diseases re: possible need for NIV launching.

- Consider modafinil for treatment if coexisting CNS alteration is suspected as the cause of EDS.

- Consider cognitive behavioral therapy or behavioral therapy for apathy; also help treat fatigue; psychostimulant treatment can be considered if apathy is associated with an impairing level of fatigue or EDS.

○ See full recommendations at myotonic.org/clinicalresources.

- Endocrine and metabolic symptoms

- Follow criteria from the American Diabetes Association re: the type of initial testing to obtain: typically, fasting blood glucose or HbAlc and if symptomatic diabetes is suspected.

- Consider formal glucose tolerance testing to monitor glucose control in patients; request serial measurement of HbAlc and fasting plasma glucose annually and coordinate care with a diabetes specialist as necessary.

o Consider treating insulin resistance with lifestyle changes in diet and exercise.

- Measure liver and bilirubin levels at baseline and annually; chronic liver enzyme elevation is typical and does not necessarily indicate the need for obtaining a liver biopsy.

$\circ$ Request thyroid stimulating hormone and circulating thyroid hormone (thyroid-stimulating hormone [TSH] and Free T4) level tests at baseline and at least every 3 years; more frequently if indicated.

- Test for hyperlipidemia through serum blood lipid levels at baseline and every 3 years; more frequently if indicated. Treat hyperlipidemia per current practice.

$\circ$ Sex-specific recommendations:

- Inquire about painful or irregular menstruation, ovarian cysts, endometriosis, and reproductive history.

- Inquire about erectile dysfunction; consider further workup and medications to treat erectile dysfunction. Consider possible cardiovascular risks-side effects associated with some erectile dysfunction medications (over the counter and prescribed).

- Inquire about infertility and family planning. 
The 2-step methodology used to drive this consensus-building process

enabled a streamlined and relatively low-cost medical guideline

\section{development process.}

O See full recommendations at myotonic.org/clinicalresources.

- Tumors

- Look for pilomatrixomas (skin tumors); refer to surgeons for safe removal.

Train patients to detect pilomatrixomas (small, a hard lump under the skin on the head, neck, arms, torso, and legs).

- Follow general population cancer screening guidelines, particularly for breast, testicular, cervical, and colon cancer.

- Evaluate suspicious new CNS, abdominopelvic, and thyroid symptoms for possible cancer; consider cancers of the brain, uterus, and ovary.

o See full recommendations at myotonic.org/clinicalresources.

\section{Conclusions}

The recommendations in this study are intended to lead to more informed and prepared clinical professionals and more readily available and high-quality care for affected families. The Consensus-based Care Recommendations support an international clinical trial environment that is better prepared to successfully assess the effectiveness of the potential therapies. The 2-step methodology used to drive this consensus-building process enabled a streamlined and relatively low-cost medical guideline development process, resulting in care recommendations available to clinicians in a timely manner.

\section{Author affiliations}

Stanley H. Appel Department of Neurology (TA), Houston Methodist Neurological Institute, TX; Centre de Recherche Charles-Le-Moyne Saguenay-Lac-St-Jean sur les Innovations en Santé (CG), Université de Sherbrooke, Jonquière, Québec, Canada; Department of Clinic Medicine (WJG), Medical University of South Carolina; Ralph H. Johnson VA Medical Center (WJG), Medical University of South Carolina, Charleston; Department of Neurology (LG), University of Iowa; Department of Neurology (NEJ), Virginia Commonwealth University, Richmond; Department of Biomedical Sciences for Health (GM), University of Milan; Department of Neurology (GM), IRCCS Policlinico San Donato, Milan, Italy; Department of Neurology (RM, SP), University of Rochester; Institute of Medical Genetics
(MTR), University Hospital of Wales, Cardiff, UK; Department of Neurology (ES), Houston Methodist Neurological Institute, TX; UMR 1129 (NA), INSERM \& Paris Descartes University, Sorbonne Paris Cité; Institute of Myology (NA), Pitié-Salpêtrière Hospital, Paris, France; Unité Clinique de Pathologie Neuromusculaire (GB), Institut de Myologie, Paris, France; Department of Pediatrics (KNB), University of Utah, Salt Lake City; Krannert Institute of Cardiology (DB), Indiana University, Indianapolis; Department of Neuroscience (MB), Brighton and Sussex Medical School, University of Sussex, Brighton, UK; Neuroimaging Laboratory (MB), IRCCS Santa Lucia Foundation, Rome, Italy; Hospice and Palliative Care Program $(\mathrm{AB})$, Iowa City VA Medical Center; Maternal-Fetal Medicine (JLBB), Clinical Genetics, Obstetrics \& Gynecology, University of Utah, Salt Lake City; Department of Paediatrics and Clinical Neurological Sciences (CC), University of Western Ontario, London, Canada; Department of Rehabilitation (EC), Radboud University Medical Center, Nijmegen, The Netherlands; Department of Neurology and Pediatrics (JWD), Stanford University, Palo Alto, CA; The NEMO Clinical Center (EDM), Fondazione Serena, Milan, Italy; Department of Cardiology (DD), Cochin Hospital, Paris-Decartes University, France; School of Medicine (TD), Stanford University, Palo Alto, CA; Department of Neurology (KE), University of Rochester, NY; Regional Pediatric Rehabilitation Center (A-BE), Queen Silvia Children's Hospital, Gothenburg, Sweden; Department of Neurology (BvE), Radboud University Medical Center, Nijmegen, The Netherlands; Department of Medicine (B. Esparis), Sleep Disorders Center, Mount Sinai Medical Center, Miami Beach, FL; Centre de Référence de Pathologie Neuromusculaire Paris-Est (B. Eymard), Groupe Hospitalier Pitié-Salpêtrière, Institut de Myologie, France; Department of Anesthesia and Perioperative Care (MF), University of California, San Francisco; Clinical Genetics Branch (SMG), Division of Cancer Epidemiology and Genetics, National Cancer Institute, National Institutes of Health, Rockville, MD; ÉCOBES (BG), Recherche et transfert, Cégep de Jonquière, Jonquière, Québec, Canada; Department of Opthalmology (TG), Georgetown University Hospital/Medstar Washington Hospital Center, Washington, DC; Department of Neurology $(\mathrm{CH})$, Center for Health and Technology (CHET), University of Rochester; Department of Neurology (JH), University of Rochester, NY; Department of Pulmonology (VH), Houston Methodist Neurological Institute, TX; Department of Neurobiology (MK), Care Sciences and Society, Karolinska Institutet; Function Area Occupational Therapy \& Physiotherapy (MK), Karolinska University Hospital; Stockholm, Sweden; Neuromuscular Clinic (WJK), London Health Sciences Center-University Campus, London, Ontario, Canada; Department of Neurology (KL), University of Utah, Salt Lake City; Department of Rehabilitation (DM), Radboud University Medical Centre, Nijmegen, The Netherlands; Hereditary Muscle Disease Unit (AM), Neurogenetics Branch, National Institute of Neurological 
Disorders and Stroke, NIH, Bethesda, MD; Departments of Pediatrics and Neurology (KDM), University of Iowa; Institute of Molecular (DGM), Cell and Systems Biology, College of Medical, Veterinary and Life Sciences, University of Glasgow, Scotland; Department of Psychiatry (DM), University of Iowa; Cardiac Electrophysiology (SN), The Hospital of the University of Pennsylvania, Philadelphia; Department of Gastroenterology and Hepatology (LN), Stanford University, Palo Alto, CA; Department of Psychiatry (PN), University of Iowa; Department of Neurology (RP), NHS Greater Glasgow and Clyde, Southern General Hospital, United Kingdom; Department of Neurology (J. Phetteplace), University of Iowa; Département of Neurological Sciences (J. Puymirat), CHUQ-site Enfant-Jésus, Québec, Canada; Department of Cardiovascular Medicine (SR), Ohio State University, Columbus; Département des sciences de la santé (LR), Université du Québec à Chicoutimi, Canada; The NEMO Clinical Center (ER), Fondazione Serena, Milan, Italy; Department of Neurology (J. Sampson), Stanford University, Palo Alto, CA; The NEMO Clinical Center (VS), Neurorehabilitation Unit, Department Biomedical Sciences for Health, University of Milan, Italy; Friedrich-Baur-Institute (BS), Department of Neurology, Ludwig-Maximilians-University, Munich, Germany; Department of Speech Pathology (LS), Houston Methodist Hospital, TX; Department of Neurology (J. Statland), University of Kansas Medical Center; Department of Neurology (SHS), McKnight Brain Institute, University of Florida, Gainesville; Division of Neurology (C. Tian), Cincinnati Children's Hospital; Department of Neurology (CT), University of Cincinnati, $\mathrm{OH}$; Department of Neurology (C. Trujillo), University of Utah, Salt Lake City; Albert Einstein College of Medicine (GT), New York, NY; Department of Medicine (GT), Division of Cardiology, John Hopkins University, Baltimore, MD; Department of Neuromuscular Disease (C. Turner), National Hospital for Neurology and Neurosurgery, London, United Kingdom and Department of Molecular Neuroscience (CT), University College London, Institute of Neurology, United Kingdom; Department of Clinical Neurological Sciences (SV), London Health Sciences Centre, University Hospital, Ontario, Canada; Stanley H. Appel Department of Neurology (AV), Houston Methodist Neurological Institute, TX; Myotonic Dystrophy Foundation (MW), San Francisco, CA; Department of Psychology (SW), University of Gothenburg, Sweden.

\section{Author contributions}

T. Ashizawa: Working Group Co-chair: Ocular, Malignancy \& Endocrine, drafting/revising the manuscript, study concept or design, data acquisition, study supervision. C. Gagnon: Working Group Co-chair: Skeletal Muscle, Rehabilitation \& Speech, drafting/revising the manuscript, data acquisition, study supervision. W.J. Groh: Working Group Chair: Cardiac, drafting/revising the manuscript, data acquisition, study supervision. L. Gutmann: Working Group Chair: End of Life
Counseling \& Management, drafting/revising the manuscript, data acquisition, study supervision. N.E. Johnson: Working Group Chair: Gastrointestinal, Myotonia \& Pain, drafting/ revising the manuscript, study concept or design, data acquisition, study supervision. G. Meola: Working Group Chair: Neuropsychiatry \& Central Nervous System, drafting/revising the manuscript, data acquisition, study supervision. R. Moxley, III: Working Group Co-chair: Ocular, Malignancy \& Endocrine, drafting/revising the manuscript, study concept or design, data acquisition, study supervision. S. Pandya: Working Group Co-chair: Skeletal Muscle, Rehabilitation \& Speech, drafting/revising the manuscript, data acquisition, study concept or design, study supervision. M.T. Rogers: Working Group Chair: Diagnosis, OBGYN \& Family Management, drafting/revising the manuscript, data acquisition, study supervision. E. Simpson: Working Group Chair: Respiratory, Excessive Daytime Sleepiness \& Anesthesia, drafting/revising the manuscript, data acquisition, study supervision. $\mathrm{N}$. Angeard: Working Group member: Neuropsychiatry \& Central Nervous System, drafting/revising the manuscript, data acquisition. G. Bassez: Working Group member: Ocular, Malignancy \& Endocrine; and Skeletal Muscle, Rehabilitation \& Speech, drafting/revising the manuscript, data acquisition. K. Berggren: Working Group member: Gastrointestinal, Myotonia \& Pain, drafting/revising the manuscript, data acquisition. D. Bhakta: Working Group member: Cardiac, drafting/revising the manuscript, data acquisition. M. Bozzali: Working group member: Neuropsychiatry \& Central Nervous System, drafting/revising the manuscript, data acquisition. A. Broderick: Working Group member: Palliative Care \& End of Life Counseling \& Management, drafting/revising the manuscript, data acquisition. J.L.B. Byrne: Working Group member: Diagnosis, OBGYN \& Family Management, drafting/revising the manuscript, data acquisition. C. Campbell: Working Group member: Diagnosis, OBGYN \& Family Management, drafting/revising the manuscript, acquisition of data. E. Cup: Working Group member: Skeletal Muscle, Rehabilitation \& Speech, drafting/revising the manuscript, data acquisition. J.W. Day: Working Group member: Diagnosis, OBGYN \& Family Management, drafting/revising the manuscript, data acquisition. E. De Mattia: Working Group member: Respiratory, Excessive Daytime Sleepiness \& Anesthesia, drafting/revising the manuscript, data acquisition. D. Duboc: Working Group member: Cardiac, drafting/revising the manuscript, data acquisition. T. Duong: Working Group member: Skeletal Muscle, Rehabilitation \& Speech, drafting/revising the manuscript, data acquisition. K. Eichinger: Working Group member: Skeletal Muscle, Rehabilitation \& Speech, drafting/revising the manuscript, data acquisition. A.-B. Ekstrom: Working Group member: Neuropsychiatry \& Central Nervous System, drafting/ revising the manuscript, data acquisition. B.G.M. van Engelen: Working Group member: Ocular, Malignancy \& Endocrine and Neuropsychiatry \& Central Nervous System, drafting/revising the manuscript, acquisition of data. B. Esparis: Working Group member: Respiratory, Excessive Daytime Sleepiness \& Anesthesia, drafting/revising the manuscript, acquisition of data. B. Eymard: Working Group member: Neuropsychiatry \& Central 
Nervous System, drafting/revising the manuscript, Acquisition of data. M. Ferschl: Working Group member: Respiratory, Excessive Daytime Sleepiness \& Anesthesia, drafting/revising the manuscript, data acquisition. S.M. Gadalla: Working Group member: Ocular, Malignancy \& Endocrine, drafting/revising the manuscript, data acquisition. B. Gallais: Working Group member: Neuropsychiatry \& Central Nervous System, drafting/revising the manuscript, data acquisition. T. Goodglick: Working Group member: Ocular, Malignancy \& Endocrine, drafting/revising the manuscript, data acquisition. C. Heatwole: Working Group member: Ocular, Malignancy \& Endocrine, drafting/revising the manuscript, data acquisition. J. Hilbert: Working Group member: Ocular, Malignancy \& Endocrine, drafting/revising the manuscript. V. Holland: Working Group member: Respiratory, Excessive Daytime Sleepiness \& Anesthesia, drafting/revising the manuscript, data acquisition. M. Kierkegaard: Working Group member: Skeletal Muscle, Rehabilitation \& Speech, drafting/revising the manuscript, data acquisition. W.J. Koopman: Working Group member: Skeletal Muscle, Rehabilitation \& Speech, drafting/revising the manuscript, data acquisition. K. Lane: Working Group member: Gastrointestinal, Myotonia \& Pain, drafting/revising the manuscript, data acquisition. D. Maas: Working Group member: Skeletal Muscle, Rehabilitation \& Speech, drafting/revising the manuscript, data acquisition. A. Mankodi: Working Group member: Gastrointestinal, Myotonia \& Pain, drafting/revising the manuscript, data acquisition. K.D. Mathews: Working Group member: Diagnosis, OBGYN \& Family Management, drafting/revising the manuscript, data acquisition. D.G. Monckton: Working Group member: Diagnosis, OBGYN \& Family Management, drafting/revising the manuscript, data acquisition. D. Moser: Working Group member: Neuropsychiatry \& Central Nervous System, drafting/revising the manuscript, data acquisition. S. Nazarian: Working Group member: Cardiac, drafting/revising the manuscript, data acquisition. L. Nguyen: Working Group member: Gastrointestinal, Myotonia \& Pain, drafting/revising the manuscript, data acquisition. P. Nopoulos: Working Group member: Neuropsychiatry \& Central Nervous System, drafting/revising the manuscript, data acquisition. R. Petty: Working Group member: Diagnosis, OBGYN \& Family Management, drafting/revising the manuscript, data acquisition. J. Phetteplace: Working Group member: Diagnosis, OBGYN \& Family Management, drafting/ revising the manuscript, data acquisition. J. Puymirat: Working Group member: Ocular, Malignancy \& Endocrine, drafting/ revising the manuscript, data acquisition. S. Raman: Working Group member: Cardiac, drafting/revising the manuscript, data acquisition. L. Richer: Working Group member: Neuropsychiatry \& Central Nervous System, drafting/revising the manuscript, data acquisition. E. Roma: Working Group member: Palliative Care \& End of Life Counseling \& Management, drafting/revising the manuscript, data acquisition. J. Sampson: Working Group member: Palliative Care \& End of Life Counseling; \& Gastrointestinal, Myotonia \& Pain, drafting/revising the manuscript, data acquisition. V. Sansone: Working Group member: Respiratory, Excessive Daytime Sleepiness \& Anesthesia, drafting/revising the manuscript, data acquisition. B. Schoser: Working Group member: Diagnosis, OBGYN \& Family Management, drafting/revising the manuscript, data acquisition. L. Sterling: Working Group member: Skeletal Muscle, Rehabilitation \& Speech, drafting/revising the manuscript, data acquisition. J. Statland: Working Group member: Gastrointestinal, Myotonia \& Pain, drafting/revising the manuscript, data acquisition. S.H. Subramony: Working Group member: Gastrointestinal, Myotonia \& Pain, drafting/ revising the manuscript, data acquisition. C. Tian: Working Group member: Ocular, Malignancy \& Endocrine, drafting/ revising the manuscript, data acquisition. C. Trujillo: Working Group member: Palliative Care \& End of Life Counseling \& Management, drafting/revising the manuscript, data acquisition. G. Tomaselli: Working Group member: Cardiac, drafting/revising the manuscript, data acquisition. C. Turner: Working Group member: Neuropsychiatry \& Central Nervous System, drafting/revising the manuscript, data acquisition. S. Venance: Working Group member: Skeletal Muscle, Rehabilitation \& Speech, drafting/revising the manuscript, data acquisition. A. Verma: Working Group member: Respiratory, Excessive Daytime Sleepiness \& Anesthesia, drafting/revising the manuscript, data acquisition. M. White: drafting/revising the manuscript, study concept or design, Obtaining funding. S. Winblad: Working Group member: Neuropsychiatry \& Central Nervous System, drafting/revising the manuscript, data acquisition.

\section{Acknowledgment}

The authors thank Dr. Julie Bolen and Natalie Street of the US Centers for Disease Control and Prevention for invaluable advice and Paul Formaker, Pam Lewis, and Margaret Wahl, R.N., for exemplary support.

\section{Study funding}

Funded by the Myotonic Dystrophy Foundation.

\section{Disclosure}

T. Ashizawa serves on scientific advisory boards for the Myotonic Dystrophy Foundation, NIH, and National Ataxia Foundation; has received funding for travel from Biohaven, PacBio, and NIH; receives research support from Myotonic Dystrophy Foundation, National Ataxia Foundation, Biohaven Pharmaceuticals, Biogen, and NIH/NINDS; he is associated with Weill Cornell Medical College (Professor), Baylor College of Medicine (Adjunct Professor), Central South University, China (Guest Faculty). C. Gagnon has received speaker honoraria from Biogen Idec; and receives research support from Bioblast Pharma, Ataxia Charlevoix-Saguenay Foundation, Fondation de ma vie, and Fonds de dotation santé Jonquière. W.J. Groh serves on the editorial board of Heart Rhythm Journal; serves as Chief of Medicine for VAMC and Cardiology Physician for Medical University of South Carolina; and receives research support from Biogen. L. Gutmann has received speaker honoraria from UC San Diego; receives publishing royalties from Up-to-Date Online; and receives research support from Alexion, NIH, and Charcot Marie Tooth Association. N. Johnson serves on scientific advisory boards 
for Cytokinetics, AveXis, AMO Pharma, and Biogen Idec; has received funding for travel and/or speaker honoraria from Strongbridge; serves as a consultant for AMO Pharma, AveXis, and Vertex Pharma; and receives research support from Ionis Pharmaceuticals, Biogen Idec, Valerion Therapeutics, Cytokinetics, Acceleron, AveXis, AMO Pharma, NIH/NINDS, FDA, Muscular Dystrophy Association, and Myotonic Dystrophy Foundation. G. Meola reports no disclosures. R. Moxley, III serves on scientific advisory boards for NIH/ NINDS and Myotonic Dystrophy Foundation; and receives research support from Ionis, NIH (NCRR, NCI), FDA, Saunders Family Foundation, and Abrams Family Fund. S. Pandya receives research support from NIH and CDC. M.T. Rogers reports no disclosures. E. Simpson receives publishing royalties for Case Files for Neurology, 3rd Edition (McGraw Hill, 2017); serves on speakers' bureaus for Alexion and Grifols; and holds an endowed chair supported by philanthropic donations. N. Angeard reports no disclosures. G. Bassez serves on scientific advisory boards for Lupin pharmaceuticals, AFMTelethon, and Myotonic Dystrophy Foundation; serves as a consultant for Lupin pharmaceuticals; and receives research support from FP7 EU, AFM-Telethon, and Myotonic dystrophy registry. $\mathrm{K}$. Berggren serves on a scientific advisory board for Biogen; and receives funding for travel and/or speaker honoraria from HDSA and FSH Society. D. Bhakta reports no disclosures. M. Bozzali serves as an Associate Editor for Journal of Alzheimer's disease and Frontiers Cellular Neuroscience; and receives research support from the Italian Ministry of Health. A. Broderick reports no disclosures. J.L.B. Byrne receives publishing royalties for Diagnostic Imaging: Obstetrics, 3rd Edition (Elsevier, 2016). C. Campbell serves on scientific advisory boards for Catabasis and PTC Therapeutics; and receives research support from Valerion Pharmaceuticals, PTC Therapeutics, Pfizer, Ionis, Eli Lilly, Prosensa, Child Health Foundation, and Jesse's Journey Foundation. E. Cup receives research support from Prinses Beatrix Spierfonds and ZonMw DoelmatigheidsOnderzoek. J.W. Day serves on scientific advisory boards for NIH, PPMD, and Marathon Pharmaceuticals; has received gifts for research from family benefactors; has served as a consultant for Biogen, Sarepta, AveXis, and Cytokinetics; has received funding for travel and/ or speaker honoraria from Cytokinetics, Biogen, Roche, AveXis, Isis Pharmaceuticals, Spinal Muscular Atrophy Foundation, Parent's Project Muscular Dystrophy, Myotonic Dystrophy Foundation, American Association of Pediatrics, PPMD, Carrel-Krusen Organization, and AMO: is author on a patent re: (1) Myotonic Dystrophy type 2 genetic testing and (2) Spinocerebellar Ataxia type 5 genetic testing; serves as a consultant for Isis, Biogen, Cytokinetics, Sarepta Therapeutics, PTC Therapeutics, AveXis, Santhera, and Pfizer; receives research support from Genzyme, Isis, Sarepta, Cytokinetics, AveXis, Biogen, Bristol-Myers, Roche, PTC Therapeutics, Wave Therapeutics, NIH/NINDS, Muscular Dystrophy Association, Myotonic Dystrophy Foundation, Spinal Muscular Atrophy Foundation, and CureSMA; and receives royalty payments for DM2 genetic testing and SCA5 genetic testing from Athena Diagnostics. E. De Mattia, D.
Duboc, and T.T. Duong report no disclosures. K. Eichinger has received funding for travel from the FSH Society and the Myotonic Dystrophy Foundation; and serves as a consultant for Ionis Pharmaceuticals, Biogen, and Acceleron Pharmaceuticals. A.-B. Ekstrom reports no disclosures. B.G.M. van Engelen serves as a consultant and clinical advisor for Fulcrum; Is author on a patent re: an IBM-specific autoantibody licensed to Euroimmun; and receives institutional support from the Radboud University Medical Centre and grant support from European Union's Horizon 2020 research and innovation programme (Murab), European Union 7th Framework Programme (OPTIMISTIC), the Netherlands Organisation for Scientific Research (NWO), The Netherlands Organisation for Health Research and Development (ZonMw), Global FSH, Prinses Beatrix Spierfonds, Spieren voor Spieren, Association Francaise contre les Myopathies, and the Dutch FSHD Foundation. B. Esparis reports no disclosures. B. Eymard has received funding for travel and/or speaker honoraria from LFB, Biogen, and BioMarin; serves as a consultant for Sarepta Pharmaceutics; and receives research support from AFM-Telethon. M. Ferschl reports no disclosures. S.M. Gadalla serves as Editor of International Journal of Chronic Diseases; and is an employee of the NIH whose work is supported by the Intramural Program of the National Cancer Institute. B. Gallais has received funding for travel from the Myotonic Dystrophy Foundation and receives research support from the Myotonic Dystrophy Foundation and Wyck Foundation. T. Goodglick reports no disclosures. C. Heatwole serves on scientific advisory boards for Biogen; has received funding for travel from Myotonic Dystrophy Foundation; serves as a consultant for Imedecs, Maximus, Johns Hopkins University, Biogen, Atyr, Ionis, Acceleron, Cytokinetics, ExpansionRX, AMO, and the Marigold Foundation; receives research support from Pfizer, Technology Development Fund (University of Rochester), Cure Spinal Muscular Atrophy, Amyotrophic Lateral Sclerosis Association, Huntington Study Group/NJ Cure HD Foundation, NIH (NIAMS, NINDS), and United States Food and Drug Administration; has royalties for use of the Myotonic Dystrophy Health Index (MDHI), a disease-specific patient-reported outcome measure for use in clinical trials and royalties from licensing instruments for FSHD, congenital DM1, CMT, SMA, and Huntington disease; and has participated in medico-legal cases. J. Hilbert receives research support from Biogen, NIH, Abrams Family Fund, FSH Society, and Friends of FSH Research. V. Holland serves on a scientific advisory board for and received funding for travel from Hill Rom; contracts with the Houston Methodist Neurologic Institute as a pulmonary specialist; serves on the speakers' bureau for Bureaus AANEM; and has served as an expert witness in a legal case regarding environmental exposures. M. Kierkegaard serves on a scientific advisory board for OPTIMISTIC; has received funding for travel from OPTIMISTIC and Muscular Dystrophy Foundation; and receives research support from Karolinska Institutet Foundation, Neuro Sweden, Einar Belvén Foundation, and Réseau provincial de recherché en adaptation. W.J. Koopman, K. Lane, and D. Maas report no 
disclosures. A. Mankodi receives support from NINDS Intramural Research Funds. K.D. Mathews serves on scientific advisory boards for NIAMS, Santhera, Sarepta, BMS, and Muscular Dystrophy Foundation; has received funding for travel from Santhera, Sarepta, and Bristol-Meyer-Squibb; serves as a consultant for Serepta Therapeutics, Bristol-MeyerSquibb, and Santhera; and receives research support from PTC Therapeutics, Sarepta Therapeutics, Pfizer, Fibrogen, Roche, Intalfarmaco, Reata, Takeda, NIH Centers for Disease Control and Prevention, and Friedreich's Ataxia Research Alliance. D.G. Monckton serves on scientific advisory boards for AMO Pharma, the Myotonic Dystrophy Support Group, the UK Myotonic Dystrophy Registry, and Myotonic Dystrophy Foundation; has received finding for travel and/or speaker honoraria from Cure Huntington Disease Initiative, European Huntington Disease Network, Muscular Dystrophy UK, University of Munich, European Neuromuscular Centre, Myotonic Dystrophy Support Group, Scottish Church Theological Society, Oxford Global, University of Iowa, 9th International Unstable Microsatellites and Human Disease Conference, Cardiff University, Vertex Pharmaceuticals, Charles River, NHS Scotland, and Biotexcel; serves as a consultant for AMO Pharma and Biogen Idec; receives research support from AMO Pharma, NIH, Cure Huntington Disease Initiative, European Huntington Disease Network, Muscular Dystrophy UK, Myotonic Dystrophy Support Group, Wellcome Trust, and Chief Scientist's Office (Scotland). D. Moser receives research support from NIH/NINDS. S. Nazarian has received speaker honoraria from Boston Scientific Inc.; serves on editorial boards for Heart Rhythm Journal and Circulation, Arrhythmia and Electrophysiology; serves as a consultant for Boston Scientific, ImriCor, Siemens, CardioSolv, and St Jude Medical; is a clinical cardiac electrophysiologist and occasionally asked to provide arrhythmia care, including electrophysiology studies, and pacemaker or ICD implantation for DM1 patients; and receives research support from Siemens, ImriCor, Biosense Webster, and NIH/NHLBI. L. Nguyen serves on a scientific advisory board for Allergan; receives publishing royalties from Up to Date; and serves as a consultant for Theravance and Genentech. P. Nopoulos receives research support from NIH (NIDCR, NINDS, NHLBI). R. Petty has received funding for travel from Myotonic Dystrophy Support Group UK. J. Phetteplace serves as a consultant for My Gene Counsel and her salary is partially funded through the Muscular Dystrophy Association. J. Puymirat and S. Raman report no disclosures. L. Richer has received funding for travel from the Myotonic Dystrophy Foundation. E. Roma reports no disclosures. J. Sampson has received funding for travel from the Myotonic Dystrophy Foundation and has provided expert testimony, not related to industry. V. Sansone reports no disclosures. B. Schoser serves on scientific advisory boards for and received funding for travel from SanofiGenzyme, Biomarin, Amicus Therapeutics, and Audentes Therapeutics; serves on the editorial boards for Neuromuscular Disorders and Journal of Neuromuscular Disorders and as
Section Editor: for Current Opinion in Neurology. L. Sterling reports no disclosures. J. Statland serves on scientific advisory boards for Sarepta, PTC, and Acceleron; has received funding for travel and/or speaker honoraria from Strongbridge; serves as a consultant for Acceleron, Fulcrum, Regeneron, and Expansion; and receives research support from NIH/NINDS and FSH Society. S.H. Subramony receives publishing royalties for Handbook of Clinical Neurology (Elsevier, 2011); performs clinical electrophysiology (20\% effort) at University of Florida Department of Neurology; and receives research support from Inonis, Reata, Horizon, Biohaven, Pharnext, Acceleron, Medosome Biotec, NIH, US FDA, Friedreich Ataxia Research Alliance, Muscular Dystrophy Association, Myotonic Dystrophy Wyck Foundation, and National Ataxia Foundation. C. Tian reports no disclosures. C. Trujillo serves on scientific advisory boards for Sarepta Therapeutics and Biogen. G. Tomaselli serves on a scientific advisory board for Amgen; serves on the editorial board for Journal of Clinical Investigation; and receives research support from $\mathrm{NIH}$ and Maryland Stem Cell Research Fund. C. Turner serves on the steering committee of the UK Myotonic Dystrophy National registry; has received speaker honoraria from Genzyme; serves on the editorial board for Neuromuscular Disorders; receives research support from Genzyme, NIHR, and LCRN; and has participated in medico-legal cases. S. Venance receives publishing royalties for Neurology in Practice. Neuromuscular Disorders (Wiley-Blackwell, 2011). A. Verma's spouse is on the speakers' bureau for UCB, Sunovion, Lundbeck, and Eisai Pharmaceuticals. M. White and S. Winblad report no disclosures. Full disclosure form information provided by the authors is available with the full text of this article at Neurology.org/cp.

\section{Appendix}

Appendix is available after References section.

Received March 12, 2018. Accepted in final form July 25, 2018.

\section{References}

1. Harper PS. Myotonic Dystrophy, 3rd ed. London: Saunders; 2001.

2. Smith MS. Single text negotiation. In: Beyond Intractability [online]. Boulder, CO: Conflict Information Consortium, University of Colorado. Available at: beyondintractability.org/essay/single-text-negotiation. Accessed July 2005.

3. A short guide to consensus building. In: The Public Dispute ProgramMassachusetts Institute of Technology [online]. Available at: web.mit.edu/publicdisputes/practice/shortguide.pdf. Accessed September 2015.

4. Nair R, Aggarwal R, Khanna D. Methods of formal consensus in classification/diagnostic criteria and guideline development. Semin Arthritis Rheum 2010;41:95-105.

5. Harvard Program on Negotiation Staff. Conflict management: a creative approach to breaking impasse. In: PON Harvard Law School [online]. Available at: pon.harvard. $\mathrm{edu} /$ daily/conflict-resolution/a-creative-approach-to-breaking-impasse. Accessed September 2015 .

6. Thornton C. Myotonic dystrophy. Neurol Clin 2014;32:705-719.

7. Chouinard MC, Mathieu J, Lavoie M, et al. Integrated care pathway tool for the myotonic dystrophy type 1. In: Myotonic Dystrophy Clinical Resources [online]. Available at: myotonic.org/sites/default/files/ICP English\%20version final.pdf. Accessed September 2015.

8. Turner C Hilton-Jones D. Myotonic dystrophy: diagnosis, management and new therapies. Curr Opin Neurol 2014;27:599-606.

9. Day JW Ferschl M, Gropper M, Moxley R. Practical suggestions for the anesthetic management of a myotonic dystrophy patient. In: Myotonic Dystrophy Clinical Resources [online]. Available at: myotonic.org/sites/default/files/MDF_LongForm AnesGuidelines_01C.pdf. Accessed September 2015 


\section{Consensus-Based Care Recommendations for Adults with Myotonic Dystrophy Type I Quick Reference Version}

The studies \& rigorous evidence needed to drive the creation of an evidence-based guideline for the clinical care of myotonic dystrophy type 1 (DM1) patients have not yet been executed for all affected body systems \& manifestations. In order to improve \& standardize care for this disorder now, more than 60 leading myotonic dystrophy (DM) clinicians in western Europe, the United Kingdom, Canada \& the United States have created the Consensus-Based Care Recommendations for Adults with Myotonic DystrophyType 1.

Summary recommendations from the Consensus-Based Care Recommendations are below. The full compendium of recommendations by body system \& their disease manifestations is available here http://www.myotonic.org/ clinical-resources.

\section{LIFE THREATENING \\ SYMPTOMS - CLINICAL CARE RECOMMENDATIONS}

\section{Surgery, anesthesia \& pain}

- See Myotonic Dystrophy Foundation's Practical Suggestions for the Anesthetic Management of a Myotonic Dystrophy Patient for anesthesia risks \& recommendations before any surgeries or procedures requiring anesthesia http://www.myotonic.org/ clinical-resources

- $\quad$ DM1 patients are far more likely to have adverse reactions to medications used for anesthesia \& analgesia; interactions of the cardiac, respiratory, muscle \& central nervous systems in each DM1 patient can lead to a variety of untoward responses before, during \& after surgery

- Serious adverse events can occur throughout the course of DM1 \& have been reported in patients whose DM1 symptoms were mild
- Behavioral \& cognitive abnormalities need careful assessment \& management preoperatively (if time permits \& if it is possible) since these manifestations along with hypersomnia $\&$ preoperative sleep deprivation can complicate the patient's immediate postoperative care \& long term recovery

- Most serious complications occur in the post-anesthesia period

- See full recommendations at http://www.myotonic.org/ clinical-resources

\section{Respiratory symptoms}

- Pulmonary complications are the leading cause of death in DM1 patients. Clinicians must monitor issues such as recurrent pneumonia at baseline \& serially with pulmonary function tests, at least forced vital capacity (FVC)

- See full recommendations at http://www.myotonic.org/ clinical-resources

Fig. 1 Respiratory Care Recommendations Flowchart

\begin{tabular}{|c|c|c|c|c|}
\hline $\begin{array}{l}\text { Asymptomatic } \\
\text { - Assess +/- } 6 \text { months } \\
\text { - If surgery is planned, reassess } \\
\text { clearance capacity. If needed, } \\
\text { possible adaptation to NIV or } \\
\text { cough assistance }\end{array}$ & $\begin{array}{l}\text { Vacci } \\
\text { - Cough assistance } \\
\text { techniques (air } \\
\text { stacking, abdominal } \\
\text { thrust, cough } \\
\text { machine) }\end{array}$ & $\begin{array}{l}\text { @ Diagnosis } \\
\text { piratory Assessment } \\
\text { or pneumonia and influenza } \\
\text { for cardiac symptoms } \\
\\
\text { Respiratory insufficiency } \\
\text { - Noninvasive } \\
\text { positive-pressure } \\
\text { ventilation using } \\
\text { ENMC workshop } \\
\text { guidelines http:// } \\
\text { www.myotonic.org/ } \\
\text { clinical-resources } \\
\text { - Supplemental } 02 \text { only } \\
\text { if necessary }\end{array}$ & $\begin{array}{l}\text { Respiratory Infection } \\
\text { - Standard medical } \\
\text { therapy } \\
\text { - Respiratory cough } \\
\text { assistance } \\
\text { - Mechanical } \\
\text { ventilation, as } \\
\text { needed } \\
\text { - Refer to pulmonary } \\
\text { medicine group }\end{array}$ & $\begin{array}{l}\qquad \\
\text { Prominent snoring, } \\
\mathrm{MIP}<60 \text {, or FVC } \\
<50 \% \\
\text { - Sleep study }\end{array}$ \\
\hline
\end{tabular}




\section{Cardiovascular symptoms}

- $\quad$ Cardiac complications are the second leading cause of death in DM1

- The most common cardiac issues are arrhythmias (sinus bradycardia, heart block, atrial fibrillation \& flutter, \& ventricular tachycardia)

- Palpitations, chest pain, dyspnea, orthopnea, lightheadedness, \& syncope warrant cardiac investigation

- Significant cardiac involvement that subsequently leads to adverse cardiac events is often asymptomatic

- Impulse or conduction abnormalities on a standard 12-lead ECG including sinus rate $<50$ BPM, PR interval $>200 \mathrm{~ms}$, QRS duration > $100 \mathrm{~ms}$, left anterior or posterior fascicular block, abnormal Q-waves, atrial tachycardia, fibrillation, or flutter, \& ventricular arrhythmias are indicative of cardiac involvement

- Refer patients with cardiac symptoms, abnormal annual or biennial ECG indicative of cardiac involvement, and patients over the age of 40 years without previous cardiac evaluation to a center experienced in DM1 care

- Cardiology referral for all DM1 patients is reasonable if part of a multidisciplinary program or if the practitioners providing primary care are uncomfortable assessing cardiac history, exam, or ECG

- See full recommendations at http://wwww.myotonic.org/ clinical-resources

\section{SEVERE SYMPTOMS \&}

\section{CONDITIONS - CLINICAL CARE RECOMMENDATIONS}

\section{Skeletal muscle weakness \& rehabilitation}

- Evaluate annually for:

- $\quad$ Swallowing \& speech difficulties

- Mobility, balance \& falls

- Activities of daily life - including self-care

- Activities in home, school, work \& community

- Refer to specialists, including PTs, OTs, speech pathologists, dietitians, social workers \& others

- $\quad$ Encourage moderate intensity (aerobic \& resistance training) exercise

- See Role of Physical Therapy in the Assessment of Individuals with Myotonic Dystrophy at wwww.myotonic.org.

- See full recommendations at http://www.myotonic.org/ clinical-resources

\section{Skeletal muscle myotonia}

- Myotonia can cause muscle stiffness, prolonged hand grip, speech \& swallowing difficulties

- Mexiletine may be considered for myotonia treatment. Mexiletine is contraindicated for DM1 patients with cardiac involvement. See full recommendations regarding mexiletine at http://www.myotonic.org/clinical-resources for more information on cardiac implications.

\section{Pregnancy \& obstetric management}

- Women with DM1:

- $\quad$ Have increased risk of miscarriage, pre-term delivery, \& respiratory insufficiency during pregnancy (especially in the 3rd trimester) \& failed labor during delivery; extreme care should be taken with analgesics \& sedating anesthetic drugs (see MDF Anesthesia Guidelines here http://www. myotonic.org/clinical-resources)

- $\quad$ Should consult with a high-risk OBGYN prior to delivery \& obtain ongoing antenatal care

- $\quad$ Fatigue much more quickly during labor \& are at risk of postpartum hemorrhage, particularly after prolonged first or second stage or if there has been polyhydramnios

- $\quad$ Should be induced only at direction of obstetrician \& after all necessary consultants assisting with the delivery are notified

- Sexually active patients with DM1:

- $\quad$ Should be referred to genetic counseling \& family planning services if of child-bearing age

- $\quad$ Should receive parental counseling for prenatal genetic diagnosis or discussion of preimplantation genetic diagnosis

- Include pediatric or neonatal specialist at delivery; intensive neonatal care is recommended for neonates that may have DM1; anticipate need for feeding tube and ventilator support

- Access to a pediatric or neonatal specialist is recommended even if fetus is known to be unaffected

- See full recommendations at http://www.myotonic.org/clinicalresources

\section{Excessive daytime sleepiness symptoms}

- $\quad$ Assess for excessive daytime sleepiness (EDS) with Epworth Sleepiness Scale or similar standardized questionnaire instrument; prescribe sleep study if sleep disturbance is suspected

- Monitor periodic limb movements (muscle activity during sleep), as well as EEG, respiratory measures during sleep study to assess possible obstructive sleep apnea \& central nervous system mediated sleep apnea

- $\quad$ Refer to pulmonologist \&/or sleep specialist if EDS scores are positive on scales

- Question patients re: alcohol or caffeine consumption medications \& sleep habits for contribution to EDS

- Evaluate impact of possible respiratory muscle weakness (forced vital capacity value sitting \& supine) on presence of EDS

- If nocturnal or daytime hypoventilation is suspected, consider non-invasive positive pressure ventilation, and refer to pulmonologist with experience in neuromuscular diseases re: possible need for NIV launching

- Consider modafinil for treatment if coexisting central nervous system alteration is suspected as the cause for EDS

- Consider cognitive behavioral therapy (CBT) or behavioral therapy for apathy; psychostimulant treatment can be considered if apathy is associated with an impairing level of fatigue or EDS

- See full recommendations at http://wwww.myotonic.org/ clinical-resources 


\section{Gastrointestinal symptoms}

- Ask about problems with chewing, swallowing, drooling, reflux, bloating, abdominal pain, bowel movement frequency \& characteristics, diarrhea \& incontinence

- Physical exam should include abdominal palpation, including around gall bladder, \& rectal exam for anal sphincter spasm \& dyssynergic defecation for symptomatic patients

- DM1 patients are at risk for pseudo-obstruction, \& experience other problems that may cause actual obstruction of small or large intestine, including endometriosis, acute gallbladder inflammation, ruptured ovarian cysts, sigmoid volvulus. Monitor potential obstructions to determine whether they are pseudo or actual \& treat accordingly

- Non-medical interventions:

- High-fiber diet for diarrhea or constipation; increase water intake

- Nutritional supplement for weight loss, weight gain or dysphagia

- Dysphagia therapy referral for oral pharyngeal dysphagia

- Medical interventions:

- Loperamide (gentle use) for diarrhea control

- Laxatives for constipation:

- First line therapy: Miralax, Senna, Ducosate or Linaclotide
- $\quad$ Second line therapy: Bisacodyl, Lubiprostone, Linaclotide

- $\quad$ Avoid oils - if above fails, refer out for anal manometry

- Metoclopramide for gastroparesis, pseudo-obstruction, reflux

- Antibiotics for bacterial overgrowth-induced diarrhea (based on breath testing)

- Enteral feeding only for recurring pneumonia or severe dysphagia causing weight loss or causing inability to swallow safely without recurrent aspiration

- Mexiletine can be considered to treat diarrhea or constipation. Mexiletine is contraindicated for DM1 patients with cardiac involvement. See full recommendations regarding mexiletine and cardiac involvement.

- See full recommendations at http://www.myotonic.org/ clinical-resources

\section{Ocular symptoms}

- Relevant eye manifestations of DM1 include cataracts strabismus \& other ocular motility problems, myopia, \& astigmatism in congenital \& juvenile-onset patients

- See full recommendations at http://www.myotonic.org/ clinical-resources

Fig. 3 Ocular Recommendations Flowchart

\begin{tabular}{|c|c|c|c|c|}
\hline $\begin{array}{l}\downarrow \\
\text { Asymptomatic } \\
\text { - Assess +/- } 1 \text { year }\end{array}$ & $\begin{array}{l}\text { Cataracts } \\
\text { - Surgically remove } \\
\text { when they interfere } \\
\text { with activities of } \\
\text { daily living } \\
\text { - Warn patients about } \\
\text { effects on driving }\end{array}$ & $\begin{array}{l} \\
\text { Dry Eye } \\
\text { - Consider ophthalmic } \\
\text { lubricants } \\
\text { - Monitor weakness } \\
\text { of eyelid closure } \\
\text { muscles affecting } \\
\text { eyelids and cornea }\end{array}$ & $\begin{array}{l}\text { Facial and eye closure } \\
\text { weakness } \\
\text { - Advise patient on } \\
\text { safety measures for } \\
\text { driving }\end{array}$ & $\begin{array}{l}\text { Ptosis } \\
\text { - Consider eyelid } \\
\text { crutches }\end{array}$ \\
\hline
\end{tabular}

\section{Tumors}

- Look for pilomatrixomas (skin tumors); refer to surgeons for safe removal

- Train patients to detect pilomatrixomas (small, hard lump under skin on head, neck, arms, torso, legs)

- Follow general population cancer screening guidelines, particularly for breast, testicular, cervical \& colon cancer

- Evaluate suspicious new CNS, abdominopelvic \& thyroid symptoms for possible cancer; consider cancers of the brain uterus \& ovary

- See full recommendations at http://www.myotonic.org/ clinical-resources 


\section{Endocrine \& metabolic symptoms}

- See full recommendations at http://www.myotonic.org/ clinical-resources

Fig. 4 Endocrine \& Metabolic Care Recommendations Flowchart

\begin{tabular}{|c|c|c|c|c|c|}
\hline $\begin{array}{l}\qquad \\
\text { Request TSH and } \\
\text { Free T4 at baseline \& } \\
\text { every } 3 \text { years, more } \\
\text { frequently if indicated }\end{array}$ & $\begin{array}{l}\checkmark \\
\text { esting } \\
\text { Test for hyperlipidemia } \\
\text { via serum blood lipid } \\
\text { levels at baseline \& } \\
\text { every } 3 \text { years; more } \\
\text { frequently if indicated }\end{array}$ & $\begin{array}{l}\text { Follow ADA guidelines } \\
\text { for diabetes testing } \\
\text { - Consider formal } \\
\text { glucose tolerance } \\
\text { testing; Serially } \\
\text { request HcA1c \& } \\
\text { FPG annually } \\
\text { - Treat Insulin } \\
\text { resistance with } \\
\text { lifestyle changes in } \\
\text { diet \& exercise }\end{array}$ & $\begin{array}{l}\text { Measure Liver \& bilirubin } \\
\text { levels at baseline \& } \\
\text { annually. } \\
\text { - Chronic liver enzyme } \\
\text { elevation is typical \& } \\
\text { does not necessarily } \\
\text { indicate need for liver } \\
\text { biopsy }\end{array}$ & $\begin{array}{l}\text { - Inquire about irregular } \\
\text { menses; ovarian } \\
\text { cysts; endometriosis; } \\
\text { reproductive history }\end{array}$ & $\begin{array}{l}\downarrow \\
\text { Males: } \\
\text { - Inquire about ED, } \\
\text { consider further } \\
\text { workup/treatment } \\
\text { - Consider possible } \\
\text { cardiovascular side- } \\
\text { effects of some ED } \\
\text { medications }\end{array}$ \\
\hline
\end{tabular}

\section{Neuropsychiatric symptoms}

- Advise patients that DM1 is also a 'brain disorder'

- Include psychiatric \& behavioral examination at baseline, \& during regularly-scheduled follow up appointments or when symptoms appear

- $\quad$ Refer patients with psychiatric or behavioral disorders, those with late-onset phenotype \& patients with cognitive complaints to mental health care professional for testing \& follow up; patients may have limited insight into these issues - consider input from partners \& family members as appropriate

- DM patients with late-onset phenotype can exhibit fast decline in certain cognitive functions

- See full recommendations at http://www.myotonic.org/ clinical-resources

\section{Acknowledgments}

This project would not have been possible without the tireless and longterm commitment made by the 64 international professionals involved in its development. The project was led by an exemplary Steering Committee of 10 members that directed the development and execution of this document. They included:

Tetsuo Ashizawa, M.D.

Houston Methodist Neurological Institute

Giovanni Meola, M.D.

Università degli Studi di Milano

Cynthia Gagnon, Ph.D.

Université de Sherbrooke

Richard Moxley, III, M.D.

University of Rochester

William J. Groh, M.D., M.P.H.

Medical University of South Carolina

Shree Pandya, D.PT

University of Rochester

Laurie Gutmann, M.D.

University of lowa

Mark Rogers, M.D.

University Hospital of Wales

Nicholas E. Johnson, M.D.

Ericka Simpson, M.D.

University of Utah

\section{Psychosocial symptoms}

Assess patient's social circumstances in household; consider \& be aware of possible child neglect, acute financial need, unsafe driving, unsafe or unsanitary home; refer to social services, support programs \& organizations

A full list of authors and an overview of the methodology used to develop consensus for these recommendations can be found here: http://www.myotonic.org/clinical-resources 


\section{Neurology ${ }^{\circ}$ Clinical Practice}

Consensus-based care recommendations for adults with myotonic dystrophy type 1

Tetsuo Ashizawa, Cynthia Gagnon, William J. Groh, et al.

Neurol Clin Pract 2018;8;507-520 Published Online before print September 13, 2018

DOI 10.1212/CPJ.0000000000000531

This information is current as of September 13, 2018

\section{Updated Information \& \\ Services}

References

Citations

Subspecialty Collections

Permissions \& Licensing

Reprints including high resolution figures, can be found at:

http://cp.neurology.org/content/8/6/507.full.html

This article cites 3 articles, 0 of which you can access for free at: http://cp.neurology.org/content/8/6/507.full.html\#\#ref-list-1

This article has been cited by 4 HighWire-hosted articles:

http://cp.neurology.org/content/8/6/507.full.html\#\#otherarticles

This article, along with others on similar topics, appears in the following collection(s):

All Cognitive Disorders/Dementia

http://cp.neurology.org//cgi/collection/all_cognitive_disorders_dementi

All Neuropsychology/Behavior

http://cp.neurology.org//cgi/collection/all_neuropsychology_behavior

Muscle disease

http://cp.neurology.org//cgi/collection/muscle_disease

Trinucleotide repeat diseases

http://cp.neurology.org//cgi/collection/trinucleotide_repeat_diseases

Information about reproducing this article in parts (figures,tables) or in its entirety can be found online at:

http://cp.neurology.org/misc/about.xhtml\#permissions

Information about ordering reprints can be found online:

http://cp.neurology.org/misc/addir.xhtml\#reprintsus

Neurol Clin Pract is an official journal of the American Academy of Neurology. Published continuously since 2011, it is now a bimonthly with 6 issues per year. Copyright Copyright (C) 2018 The Author(s). Published by Wolters Kluwer Health, Inc. on behalf of the American Academy of Neurology.. All rights reserved. Print ISSN: 2163-0402. Online ISSN: 2163-0933.

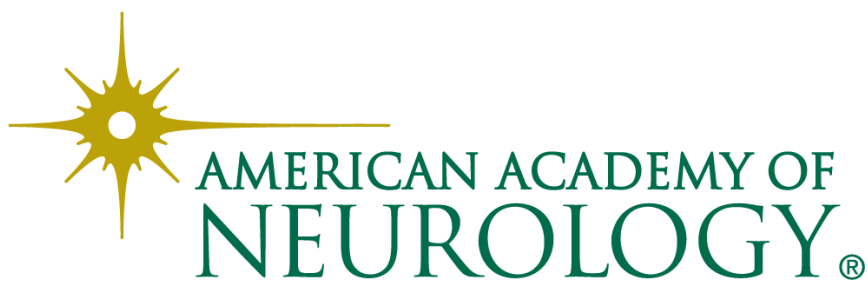

